\title{
TATA RUANG IBUKOTA TERAKHIR KERAJAAN GALUH (1371 - 1475)
}

\section{THE SPATIAL PLANNING OF THE LAST CAPITAL CITY OF THE GALUH KINGDOM (1371 - 1475 AD)}

\author{
Budimansyah $^{1}$, Nina Herlina Lubis ${ }^{2}$, Miftahul Falah ${ }^{3}$ \\ 1,2,3 Departemen Sejarah dan Filologi, Fakultas Ilmu Budaya Universitas Padjadjaran \\ Jl. Raya Bandung-Sumedang Km. 21 Jatinangor, Kabupaten Sumedang \\ e-mail: ${ }^{1}$ suwardi.budiman@gmail.com, ${ }^{2}$ ninaherlinalubis@ gmail.com. \\ ${ }^{3}$ miftah.alfalah72@gmail.com
}

DOI: $10.30959 /$ patanjala.v12i2.596

\begin{abstract}
Abstrak
Penelitian ini bertujuan untuk menguak tata ruang Galuh Pakwan sebagai ibukota terakhir Kerajaan Galuh, sejauh mana pola ruang kota tersebut berkaitan dengan nilai-nilai kelokalan sebagaimana tergambar dalam historiografi tradisional. Dalam penelitian ini metode sejarah akan dipergunakan sebagai fitur utama agar menghasilkan suatu hasil kajian yang komprehensif, dan menggunakan teori tata kota, serta metode deskriptif-kualitatif. Minimnya sumber terkait sejarah Galuh Pakwan, wawancara secara mendalam kepada para narasumber diharapkan bisa menjadi suatu bahan analisis historis. Berdasarkan fakta di lapangan, Galuh Pakwan sebagai ibukota kerajaan berawal dari sebuah kabuyutan. Pada masa pemerintahan Niskalawastu Kancana, kabuyutan tersebut dijadikan pusat politik dengan tetap menjalankan fungsi kabuyutannya. Seiring waktu, Galuh Pakwan menjelma menjadi sebuah kota yang tata ruangnya menunjukkan representasi dan implementasi konsep kosmologi Sunda. Galuh Pakwan terbentuk oleh pola radial-konsentris menerus, sebagai gambaran kosmologi Sunda sebagaimana terungkap dalam naskah-naksah Sunda kuna.
\end{abstract}

Kata kunci: Galuh Pakwan, kosmologi Sunda, Kabuyutan, tata ruang, morfologi kota.

\begin{abstract}
The research is not only aimed at uncovering the spatial layout of Galuh Pakwan as the last capital of Galuh Kingdom, but also at exploring how well the relationship between the urban spatial patterns and the local values as depicted in the traditional historiography. Beside having the historical methods as the main feature to produce a comprehensive study result, the study also uses the urban planning theory, as well as the descriptive qualitative methods. The historical sources related to the history of the Galuh Pakuan are very limited. As a result, the in-depth interviews with the resource persons are expected to be appropriate as the observation material for historical analysis. Based on the facts found in the field, the Galuh Pakwan as the capital of the kingdom originated from a Kabuyutan. During the reign of Niskalawastu Kancana, Kabuyutan served as a political center while maintaining its original function as Kabuyutan. As the time passed, the Galuh Pakwan was transformed into a city whose spatial layout represented and implemented the Sundanese cosmological concept. The Galuh Pakwan was formed by a
\end{abstract}


continuous radial-concentric pattern, as a description of Sundanese cosmology in the ancient Sundanese manuscript.

Keywords: Galuh Pakwan, Sundanese cosmology, kabuyutan, spatial planning, city morphology.

\section{A. PENDAhuluan}

Pokok permasalahan dalam penelitian ini, yaitu bagaimana pola tata ruang Kota Galuh Pakwan dan sejauh mana pola tersebut berkaitan dengan nilai-nilai kelokalan sebagaimana tergambar dalam historiografi tradisional? Tujuan penelitian ini adalah untuk menjelaskan pola tata ruang Kota Galuh Pakwan dan sejauh mana pola tersebut berkaitan dengan nilai-nilai kelokalan sebagaimana tergambar dalam historiografi tradisional.

Kajian terkait Galuh Pakwan sebagai ibukota terakhir Kerajaan Galuh sangat penting, mengingat masih minimnya historiografi kota kuno Nusantara, yang diharapkan bisa menjadi pembanding terhadap "tudingan" dari beberapa ahli yang menyimpulkan bahwa budaya tata kota di Nusantara diperkenalkan oleh pemerintah Hindia Belanda.

Widyonugrahanto dkk. (2017) dalam artikelnya "The Politics of Sundanese Kingdom Administration in Kawali-Galuh" sebagai hasil penelitian program Academic Leadership Grant Universitas Padjadjaran 2015-2018, menghasilkan kesimpulan bahwa Kawali merupakan ibukota terakhir Kerajaan Galuh yang kemudian secara fungsinya dipindahkan oleh Prabu Dewataprana ke Kota Pakwan Pajajaran. Sesuai dengan judulnya, dalam artikel tersebut hanya memberikan penekanan pada wilayah politik masa Kerajaan Galuh, terutama tentang konsep pembagian kekuasaan, dan tata ruang Kota Galuh Pakwan hampir tidak dibahas sama sekali.

Lalu pada November 2019, Etty Saringendyanti dkk. membuat laporan penelitian "Tata Ruang Keraton Galuh (IX-X M) dan Keraton Surawisesa (XIV-XV M)". Kegiatan yang dilaksanakan oleh Balai Arkeologi Jawa Barat ini menghasilkan temuan bahwa tinggalan-tinggalan arkeologis dan toponimi di wilayah Kawali sebagai pembentuk ruang Kota Galuh Pakwan. Namun temuan tersebut tidak sampai menghasilkan peta tata ruang kota.

Dalam studi sejarah modern untuk merekonstruksi kondisi Kota Galuh Pakwan tidak hanya cukup dengan melakukan uraian secara genetis, tetapi diperlukan juga pendekatan multidisiplin. Pendekatan tersebut dapat dilakukan dengan meminjam konsep dan teori dari ilmu-ilmu sosial karena memiliki daya analisis lebih besar untuk mencari kondisi-kondisi kausal dari peristiwa sejarah sehingga dapat memperkuat analisis masalah (Kartodirdjo, 1992: 2).

Perkembangan ilmu pengetahuan yang sangat cepat pada saat ini melahirkan paradigma baru dalam pendekatan analisis untuk penelitian ilmiah. Pada praktiknya, proses penelitian yang dilakukan idealnya harus menggunakan pendekatan transdisiplin. Sabine Hoffmann, Christian Pohl, dan Janet G. Hering (2017: 1-2) mengatakan bahwa pendekatan transdisiplin merupakan konsep yang multi-perspektif yang melampaui batasbatas keilmuan tertentu, sebagai jembatan terhadap semua disiplin ilmu untuk menghasilkan solusi yang lebih tajam terhadap masalah-masalah yang akan menjadi fokus penelitian. Lalu Brian M. Belchera dkk. (2019: 195) menambahkan bahwa pendekatan transdisiplin dapat memberikan penilaian yang relevan dan kredibel secara efektif dalam proses penelitian. Hal tersebut karena semua permasalahan yang sedang dianalisis akan ditinjau dari segala sudut berbeda, untuk menghasilkan kesimpulan yang berdimensi luas dan benar-benar baru. Untuk menghasilkan kesimpulan yang tajam dan holistik, maka pendekatan melalui ilmu sosiologi, arkeologi, filologi, antropologi, planologi, dan toponimi diharapkan bisa menjadi pisau analisis yang tepat, agar bisa mengekstrapolasikan berbagai fakta terkait dengan Galuh Pakwan pada masa lampau sebagai pusat pemerintahan Kerajaan Galuh secara lebih komprehensif. 
Galuh Pakwan sebagai jantung Kerajaan Galuh merupakan kota yang direncanakan dengan kondisi fisik bentang alam kawasannya sebagai pertimbangan utama, dan dirancang dengan konsep kelokalan serta memanfaatkan kondisi topografis dan geologis yang diselaraskan dengan kosmologi lokal. Rully Damayanti dan Handinoto (2005: 35); serta Ofita Purwani (2017: 74) menulis, kota-kota di Pulau Jawa masa pra-kolonial pada dasarnya menganut pola kota mandala, sebagai keberlanjutan dari tradisi kota-kota pada masa Hindu-Buddha, yang selalu memiliki "pusat" (inti) kota yang berupa istana penguasa (kerajaan atau kabupaten) dengan alun-alun dan bangunan penting lain di sekitarnya. Miftahul Falah (2018: 43-45) berpendapat bahwa, keselarasan dengan menghadirkan harmonisasi jagat raya diciptakan berdasarkan kosmologi dari manusianya. Oleh karena itu konsep makrokosmos dan mikrokosmos merupakan suatu kesatuan yang selalu ada di dalam desain tata ruang pada kota-kota lama yang ada di Pulau Jawa.

Struktur kerajaan pada masa HinduBuddha merupakan cerminan dari mitologi alam semesta, dimana sosok sang penguasanya meraih suatu legitimasi dengan jalan menerjemahkan konsep mandala ke dalam sebuah kota pusat. Mandala tersebut berfungsi sebagai kerangka geopolitik, yang secara politis menjadi pelindung sang penguasa sebagai manusia pilihan dari para dewa (dalam banyak kisah, raja-raja pada masa Hindu-Buddha mengaku dirinya sebagai keturunan para dewa). Model kerajaan dengan konsep kota mandala tersebut oleh Clifford Geertz (1980) dinamakan sebagai a Theater State (Young, 2016: 17).

Dalam kosmologi tata ruang kota dengan tradisi Hindu, tatanan manusia selalu diwujudkan pada proses awal penciptaan dunia, yang pada akhirnya menghasilkan tata ruang kota sebagai refleksi dari "ruang para dewa". Hal tersebut merupakan manifestasi elemen transendental yang bersifat paralel antara makrokosmos (alam para dewa) dengan mikrokosmos (alam manusia, yang dalam hal ini adalah sebuah kota), yang pada bagian sentralnya akan selalu terdapat sebuah sumbu penghubung (axis mundi) sebagai "media komunikasi" di antara kedua alam tersebut (Singh, 1993: 239-240).

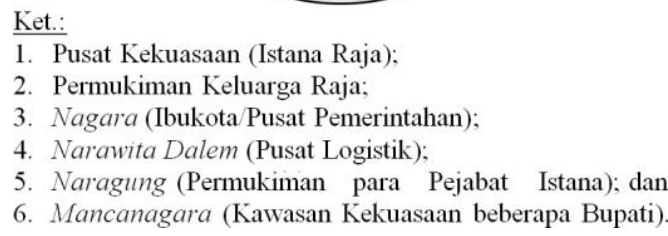

Gambar 1. Pola Mandala pada Kota Jawa Sumber: Damayanti dan Handinoto, 2005: 35.

Berbeda dengan kota-kota yang berakar pada tradisi Hindu-Buddha, Kota Galuh Pakwan adalah sebuah produk budaya dari masyarakat Sunda pada masa lampau (pra-kolonial) dengan konsep tata ruang kota "modern" yang bersinergi dengan alam setempat. Arief Sabaruddin (2012: 41-41) mengatakan bahwa dalam merancang karya arsitektur, manusia pembuatnya diharapkan memiliki kesadaran secara tinggi terhadap dimensi ekologi, agar karya arsitektur tersebut menjadi selaras dengan kaidah-kaidah arsitektur berkelanjutan, yang merupakan bagian dari kearifan lokal.

Pemahaman akan keberagaman dan nilai-nilai budaya lokal merupakan bagian penting selain dimensi ekologi. Hal tersebut adalah sebagai akar bagi seluruh masyarakat di dunia ini, tak terkecuali masyarakat Sunda pada masa lampau, agar bisa dengan jelas dalam melihat, mengalami, dan bertindak atas lingkungan mereka sebagai esensi dari rasa memiliki yang sangat tinggi (Umemoto dan Zambonelli, 2012: 198).

Galuh Pakwan tidak hanya memiliki peran penting karena statusnya sebagai 
ibukota kerajaan, namun juga memiliki fungsi sebagai identitas sosial dan budaya. Kota pusat pada suatu negara/kerajaan adalah tempat dimana simbol dan budaya menjelma sebagai memori kolektif masyarakatnya. Kota pusat seperti ini pula berperan sebagai tempat interaksi tertinggi di antara seluruh pemangku kebijakan yang akan melahirkan sistem politik, ekonomi, dan sosial-budaya dalam gerak roda pembangunannya. Menurut Gottmann dan Harper (1990), tipikal kota seperti tersebut akan sangat berpengaruh terhadap masa yang sedang berlangsung dan masa yang akan datang pada sebuah bangsa, dan kemelekatannya sebagai simbol akan menjadi parameter kebesaran bangsanya (Mayer dkk., 2016: 11-12).

\section{B. METODE PENELITIAN}

Metode sejarah adalah fitur utama yang akan dipergunakan dalam penelitian ini, yang diawali dari tahap heuristik, yaitu melakukan penelusuran sumber primer dan sekunder, lalu tahap kritik dan interpretasi terhadap sumber, dan historiografi sebagai tahap akhir untuk menuliskan peristiwa masa lampau agar menjadi sebuah kisah sejarah yang kronologis dan imajinatif, yang secara keseluruhan merupakan satu kesatuan yang utuh (Gottschalk, 2006: 33-34).

Peter J. Buckley (2016: 879) mengatakan bahwa metode sejarah sebagai pendekatan historis sangat tepat untuk menghasilkan suatu hasil kajian yang komprehensif, karena memiliki analisis kritis yang bisa diterapkan terhadap semua sumber terkait. Hal tersebut sejalan dengan apa yang pernah ditulis oleh Bodin (1566) di dalam Advocati: Methodvs Ad Facilem Historiarvm Cognitionem. Ia berpendapat bahwa untuk merekonstruksi sebuah peristiwa di masa lampau harus diawali dengan mengkritisi sumber-sumber yang akan diambil, agar menghasilkan suatu informasi yang tidak diragukan dari masa lampau tersebut (Lorenz, 2001: 6870).

Selain memakai teori-teori sosial, dalam penelitian ini juga akan menggunakan teori dan konsep tata kota serta metode deskriptif-kualitatif. Ion Albulescu (2018:
186) berpendapat bahwa sebuah penelitian tidak harus terpaku pada penggunaan satu jenis pendekatan metodologi saja. Penggunaan lebih dari satu metode dalam suatu penelitian akan mempertajam analisis dan menghasilkan sebuah kesimpulan yang holistik.

Ruang wilayah sebagai suatu produk historis tercipta dari sebuah proses pembentukan wacana-wacana sebagai entitas yang dinamis dan sangat subjektif. Ruang wilayah dalam arti yang paling luas di pahami sebagai state (negara/kerajaan), yang memiliki hubungan antara subjek (individual atau kelompok), mediator (wilayah abstrak atau wilayah konkret) dan objek (realitas fisik konkret di luar subjek atau kemampuan individual yang dapat memproyeksikan dirinya ke dalam peran lain) (Dhona, 2016: 2).

Sebuah kota merupakan simbol peradaban dan budaya suatu bangsa, sebagai pusat "energi" dan kebudayaan seluruh penghuninya. Kota juga adalah suatu bentuk dan simbol hubungan sosial yang terintegrasi dari semua elemennya, yaitu: pusat pemerintahan, peribadatan, perekonomian, pendidikan, dan keamanan (Paddison, 2001: 11). Allen J. Scott dan Michael Storper (2015: 4) menambahkan bahwa sebuah kota adalah kumpulan dari segala fungsi ekonomi, sosialbudaya, dan politik, yang memiliki batasan luas wilayah tertentu. Kota seperti itu lahir dari suatu kelompok masyarakat dengan akar budaya agraris.

Berdasarkan luas wilayahnya, terdapat dua istilah dalam bahasa Inggris untuk mendefinisikan suatu kota yaitu city dan town. City secara pragmatis memiliki dimensi yang lebih besar dari town, namun untuk penyebutan suatu wilayah yang memiliki populasi lebih dari lima juta disebut sebagai super city, dan untuk wilayah yang berkedudukan sebagai kota induk (dan tidak selalu memiliki peran sebagai ibukota negara) dinamakan dengan metropolitan (Lubis dkk., 2000: 1; Budimansyah, Sofianto, dan Dienaputra, 2018: 423-444).

Berangkat dari alasan akan minimnya sumber sejarah Galuh Pakwan, maka wawancara secara mendalam (indepth 
interview) kepada para narasumber di lapangan, terutama terkait toponimi di wilayah Kecamatan Kawali dan sekitarnya. Narasumber yang akan dimintai informasinya adalah para pewaris budaya, para tokoh pelaku budaya, dan para juru kunci situs, yang tentunya sejalan dengan lima persyaratan dalam memilih narasumber yaitu: narasumber tersebut terenkulturasi penuh dengan kebudayaan yang diwarisinya, terlibat secara langsung dalam peristiwa historis/budaya yang akan diteliti, memiliki pengetahuan yang detail terkait kondisi historis/budaya yang tidak diketahui/dipahami oleh peneliti, memiliki keterlibatan waktu yang cukup dalam penelitian, dan di dalam informasi yang diberikan mempergunakan bahasa lokal sehingga bisa memberikan perspektif yang baru di luar kesimpulan para ahli terhadap sejarah Galuh secara umum (Muhsin Z., Mahzuni, dan Septiani, 2019: 438).

\section{HASIL DAN BAHASAN}

\section{Kompleks Keraton Surawisesa}

\section{a. Konsep Kabuyutan' dalam Tradisi} Sunda

Menurut Richadiana K. Kartakusuma (2012: 1) sebagaimana ia mengutip pendapat Zoetmulder, suatu kebudayaan tidak akan bisa terlepas dari pengaruh agama pemangku budayanya. Dalam kebudayaan Sunda kuna "tradisi megalitik"

1 Buyut merupakan istilah hubungan yang digunakan oleh masyarakat Sunda kepada nenek moyangnya (atau keturunannya) pada generasi keempat. Kata buyut juga memiliki pengertian sebagai sesuatu yang sakral (Rigg, 1861: 75). Kabuyutan bisa didefinisikan sebagai lokasi atau tempat yang disakralkan menurut aturan (keraton/istana, tempat keagamaan, permakaman, dsb.) (Darsa, 2015: 17). Kabuyutan juga mengacu kepada dimensi gaib atau suci, yang bersifat tangible (fisik) ataupun yang bersifat intangible (makna dari sebuah wujud fisik), atau sebuah tempat di mana wujud fisik tersebut berada. Wujud fisik tersebut bisa sebagai manusia, situs (lahan, lokasi, tata ruang alam), atau benda-benda yang dianggap memiliki daya magis seperti: keris, pohon yang berumur tua, tempat pertapaan, dan gunung-gunung (Saringendyanti, 2018: 52). adalah perwujudan dari pengaruh landasan nilai spiritual para karuhun yang merupakan kunci guna lebih mengenali jati diri kepribadian budaya dan bangsa. Sunda yang wiwitan dengan aspek dan perangkat simbolnya disebut dengan nama kabuyutan. Hingga masa Hindu-Buddha, di Tatar Sunda banyak ditemukan sejumlah bangunan berundak yang sebagian besar menempati bukit, gunung atau dataran tinggi, dan lingkungan pegunungan yang disebut parahyangan. Bentuk lain dari landasan nilai spiritual adalah batu datar atau batu tegak yang ditempatkan begitu saja pada suatu bukit atau teras-teras dengan elevasi rendah pada suatu dataran tinggi dengan orientasi ke gunung tertentu.

Tradisi megalitik adalah sebuah produk budaya manusia pada masa lampau yang lahir secara serempak hampir di seluruh benua. Tradisi ini telah dimulai pada peralihan periode mesolitik dengan neolitik, yang rata-rata ditemukan pada daerah berkontur serta banyak terdapat sumber-sumber untuk menunjang kelangsungan hidup (air, hewan, dan tumbuhan). Kondisi alam sebagai tempat ritus tradisi megalitik dipilih dengan pertimbangan kosmologi melalui tandatanda yang didapat dari alam (Tolla, 2014: 136). Sudarti Prijono (2015: 69) menambahkan bahwa masyarakat masa lampau memilih lokasi bermukim dengan mengikuti pola dan zona tertentu, dan sumber daya air menjadi pertimbangan utama dalam budaya megalitik, hal ini terlihat dengan pola penempatan situs yang mengikuti aliran sungai. Permukiman dan sumber daya alam sebagai penopang kehidupan masyarakat pada masa lampau tidak akan bisa dilepaskan dari memanfaatkan sumber daya alam untuk mendukung kehidupan religi dan ritual yang mereka jalankan.

Sungai dan lahan yang subur di sekitarnya merupakan sumber kehidupan penting bagi segenap makhluk hidup. Jejak kehidupan dari masa prasejarah banyak ditemukan pada daerah pinggiran sungai, seperti fosil hewan, kerangka manusia, 
alat-alat batu, dan tinggalan lainnya sebagai pendukung kehidupan manusia pada masa tersebut. Pada saat pengaruh Hindu masuk ke wilayah Nusantara, kehidupan di wilayah sekitar sungai masih tetap berlangsung. Pada masa lampau, sungai tidak hanya sebagai tempat pemenuhan kebutuhan hidup dan transportasi, melainkan juga sebagai tempat untuk membersihkan, mensucikan, dan menyuburkan, sebagai bagian dari kepercayaan terhadap daya magis (Savitri, 2015: 37-46)

Secara esensi punden berundak sebagai salah satu produk dari kebudayaan Sunda kuna merupakan perwujudan dari mandala, landasan penting yang membebaskan manusia dari dikotomi subjek-objek semesta. Manusia menurut konsep ini adalah mikrokosmos (replika-bagian) dari makrokosmos. Dalam ajaran jatisunda, tri tangtu dipahami sepenuhnya levels of being. Manusia Sunda mengenal dan mengetahui kemana akan menuju, serta tujuan akhir yang akan dicapai pada akhir hidupnya dari jenjang-jenjang tersebut. Mandala sebagai tri tangtu di buwana begitu melekat dengan alam, ajaran ini merupakan amanat dari karuhun Sunda bahwa "apa yang telah ada tidak boleh diubah, namun tetap dihormati sebagaimana adanya". Ajaran karuhun Sunda yang sangat ekologis, melahirkan konsep "bangunan pertama" yang hampir selalu ditempatkan pada lahan tertinggi, yang berbentuk punden berundak yang tetap difungsikan sesuai dengan fungsinya sampai saat ini (Kartakusuma, 2012: 2-5). Punden berundak sebagai tempat ritus berupa sebuah bukit sebanyak tujuh undakan, semakin tinggi undakan maka secara nilai akan semakin tinggi dan suci. Tiap sisi undakan terdapat menhir, dan pada bagian puncak undakan terdapat arca (Permana, 2006: 89-90).

\section{b. Dari Kabuyutan Menjadi Pusat Politik}

Pada 1357 M terjadi peristiwa dalam perjalanan sejarah Sunda dan Jawa yaitu Pasunda Bubat ${ }^{2}$, peristiwa ini terdapat di dalam naskah Pararaton yang ditulis pada abad ke-15 M (Herlina, 2017). Kisah yang sangat dipercaya oleh para ahli sejarah kuno ini terjadi di utara Kota Majapahit tersebut diuraikan secara gamblang. Pasunda Bubat, selain dalam Pararaton, kisahnya terdapat pula dalam Kidung Sundayana dan Kidung Sunda, serta naskah Carita Parahyangan meski tidak terperinci (Munandar, 2017).

Pasunda Bubat tidak menyisakan satu pun seluruh rombongan yang berangkat dari Kerajaan Galuh, hal ini menyebabkan terjadinya kekosongan kepemimpinan beserta para aparatur kerajaan untuk tetap menjalankan gerak pemerintahan. Undang A. Darsa (2011: 8990) yang merujuk pada naskah Carita Parahyangan mengatakan bahwa Niskalawastu Kancana baru berumur tujuh tahun pada saat ditinggal oleh kedua orang tua beserta kakaknya. Dikarenakan umurnya yang belum cukup untuk naik takhta menggantikan ayahnya, maka untuk sementara posisi raja diduduki oleh pamannya, yaitu Bunisora Suradipati. Selain menjadi raja sementara, Bunisora juga bertugas sebagai wali negara yang mengasuh dan mendidik Niskalawastu Kancana untuk dipersiapkan sebagai putra mahkota yang nantinya akan naik takhta. Atas didikan pamannya tersebut, Niskalawastu Kancana menjadi sosok yang matang (koloteun), taat dalam menjalankan agama, pintar dalam ilmu kenegaraan dan keprajuritan, bijaksana, merupakan sosok yang ideal untuk menjadi seorang raja. Nina Herlina Lubis, dkk. (2016: 11) menulis bahwa pada saat naik takhta,

\footnotetext{
2 Sampai pada saat ini masih banyak yang mengartikan Pasunda Bubat sebagai "Perang Bubat". Arti yang paling mendekati adalah "suatu peristiwa yang terjadi di Bubat", yaitu sebuah area lapang di wilayah Majapahit.
} 
Niskalawastu Kancana memindahkan pusat pemerintahan dari Bojong Galuh (Karangkamulyan) ke Kawali yang bernama kadatuan Surawisesa. Dalam prasasti Kawali I disebutkan bahwa ia memperbaiki kompleks keraton yang memang telah ada, serta membuat saluran/parit sebagai fungsi pertahanan.

Saluran sebagai fungsi irigasi (pengairan pertanian), penanggulangan bencana alam, ataupun fungsi pertahanan lahir dari masyarakat yang sudah mempunyai pengetahuan yang maju, serta peran sentral dari otoritas seorang raja, karena dibutuhkan organisasi dan mobilisasi massa yang besar, juga birokrasi yang cepat untuk merealisasikannya. Kebijakan raja dalam hal pembuatan saluran/parit seperti yang terjadi di Tarumanagara, ternyata hampir sama terjadi di kerajaan-kerajaan lain di Asia Timur, yang melahirkan pemahaman dengan apa yang disebut oleh Witffogel (1957) sebagai "masyarakat hidrolik" dan oriental despotisme sebagai faktor pembentuk negeri (Wibisono, 2013: 55).

Pembuatan saluran/parit yang dilakukan oleh masyarakat pada masa lampau, sejatinya merupakan aksi nyata dari konsep konservasi alam, yang dalam hal ini adalah konservasi air. Susilawati (2006: 33) berpendapat bahwa bentuk konservasi tanah dan air sebagai upaya penyelamatan bumi, sebagai tindakan untuk mengembalikan ekosistem tanah dan air, sangat penting untuk dilakukan demi menyelamatkan kehidupan yang menyertainya. Konservasi tanah dan air adalah dua hal yang saling berkaitan. Ketersediaan kuantitas dan kualitas air yang berkelanjutan, merupakan parameter dari keberhasilan tindakan konservasi alam terhadap tanah secara terpadu.

Dengan selesainya perbaikan dan perkuatan kompleks Keraton Surawisesa yang dilakukan oleh Prabu Niskalawastu Kancana, tempat tersebut kemudian dijadikan sebagai pusat pemerintahan. Dengan demikian wilayah Kawali tidak lagi hanya berfungsi sebagai kabuyutan, melainkan juga berfungsi sebagai pusat pemerintahan. Selanjutnya kedudukan raja di Keraton Surawisesa digantikan oleh putranya yaitu Dewa Niskala yang memerintah hanya selama tujuh tahun (1475-1482 M). Saat menjadi raja, Dewa Niskala melakukan pelanggaran karena menikahi "perempuan larangan" (Darsa, 2011: 90; Dipraja, 2017). Karena kesalahan tersebut Dewa Niskala digantikan oleh anaknya yaitu Jayadewata (Isnendes, 2005: 3; Darsa, 2011: 90-91; Muhsin Z., 2011: 13; Dipraja, 2017). Lalu ia pun mewarisi pula takhta Kerajaan Sunda pada saat dinikahkan dengan Kentring Manik Mayang Sunda, dan dinobatkan dengan gelar Sri Baduga Maharaja Ratu Aji di Pakwan Pajajaran Sri Ratu Déwata (Danasasmita, 2012: 65; Darsa, 2011: 92).

\section{c. Kompleks Keraton Surawisesa}

Keraton Surawisesa menjalankan fungsi pemerintahan sebagai ibukota Kerajaan Galuh pada saat Niskala Wastukancana berkuasa (1371 - $1375 \mathrm{M})$, hal ini berdasarkan informasi yang tertulis pada prasasti Kawali I dan naskah Carita Ratu Pakuan (Lubis, dkk., 2013: 181).

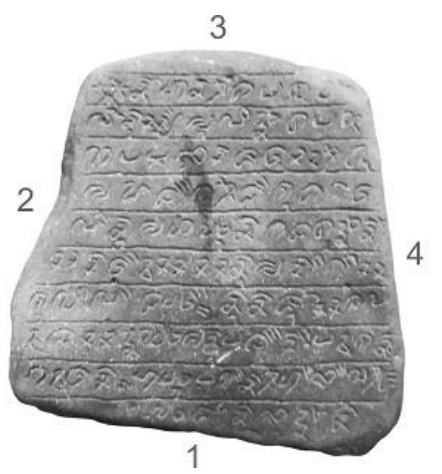

Gambar 2. Bagian Muka Prasasti Kawali I Sumber: Dok. Budimansyah, September 2017.

Terjemahan bagian muka menurut pembacaan Djafar sebagaimana dikutip oleh Lubis, dkk., (2013: 15) menjelaskan: inilah jejak (tapak) kawa-li yang Mulia tapa ba-ga Parebu Raja Wastu, bertahta di benteng Kawa-li yang memperindah Kadatuan 
Surawisesa, yang mendirikan pertahanan di sekeliling [kerajaan] dan yang menyuburkan seluruh wilayah pemukiman, kepada yang datang hendaknya menjaga keindahan tempat ini agar berja-ya di dunia.

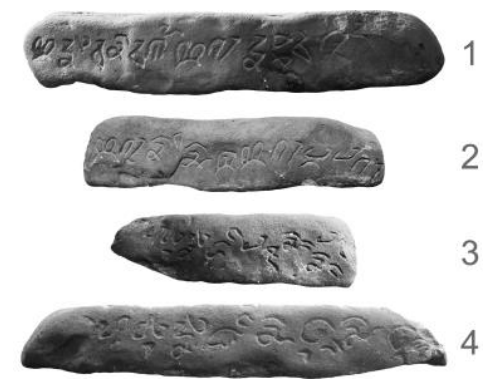

Gambar 3. Bagian Tepian Prasasti Kawali I Sumber: Dok. Budimansyah, September 2017.

Teks bagian tepian menurut pembacaan Djafar dan terjemahan Ayatrohaedi sebagaimana dikutip oleh Lubis, dkk. (2013: 15) menjelaskan:

"jangan dimusnahkan!

jangan disemena-menakan!

ia dihormati ia tetap

ia diinjak ia roboh".

Sementara itu, menurut isi naskah Carita Ratu Pakuan (Darsa, 2007: 204205), yang lebih bercerita tentang penggambaran tata ruang arsitektur di dalam kompleks Keraton Surawisesa adalah sebagai berikut:

...Sekepergiannya dari istana timur, pelataran keraton timur, Si Mahut Putih Gedemanik. Mayadatar namanya. Sunialaya namanya, istana

Sri Kancana Manik, rumah berukir dibuat gemerlapan, di Sanghiyang Pandan Larang, istana Si Pawindu Hurip. Rumah pertama yang penuh ukiran, yang kedua penuh hiasan, yang ketiga rumah dibentuk halus, yang keempat berbentuk limas kumureb, yang kelima tembus pandang sejagat, yang keenam rumah tepep, yang ketujuh anjungan pagoda, yang kedelapan berumpak sembilan, yang kesembilan berkilauan. Anjungan berderet dengan bale-bale, bale-bale berderet dengan anjungan, namanya istana Kalangsu. rumah Permata Gemerincing, namanya Ganggang Hotapih. Gemerisik di sanghyang Sumur Bandung...

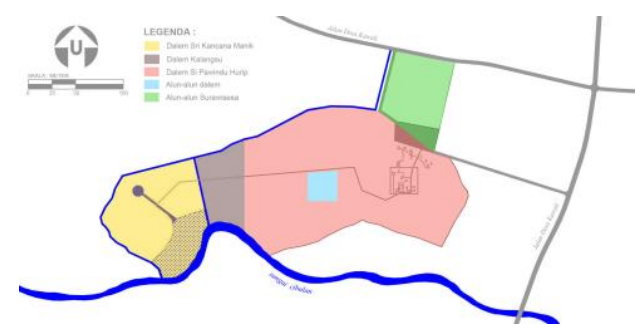

Gambar 4. Zona Ruang Keraton Surawisesa Sumber: Lubis, dkk., 2013.

Tata ruang kompleks Keraton Surawisesa terdiri dari tiga zona, yaitu Keraton Sri Kancana Manik (Dalem Sri Kancana Manik), Keraton Kalangsu (Dalem Kalangsu), dan Keraton $\mathrm{Si}$ Pawindu Hurip (Dalem Si Pawindu Hurip), yang melintang dari arah timur laut-barat daya mengikuti kontur bukit (Lubis, dkk., 2013: 218). Keraton Sri Kancana Manik merupakan area sakral (istana dan tempat beribadah raja), sedangkan Keraton $\mathrm{Si}$ Pawindu Hurip sebagai area profan (terdiri dari bangunan-bangunan fungsi publik), dan Keraton Kalangsu berfungsi sebagai ruang transisi. Konsep pembagian tata ruang antara ruang privat, ruang transisi dan ruang publik (sakral - transisi - profan) dipakai hampir di seluruh kota kuno di Nusantara. Dari uraian tersebut didapat gambaran tentang urutan tata ruang kompleks Keraton Surawisesa, baik dari segi pembagian zona fungsi ruang dengan area transisinya, maupun orientasi secara kosmologisnya. 


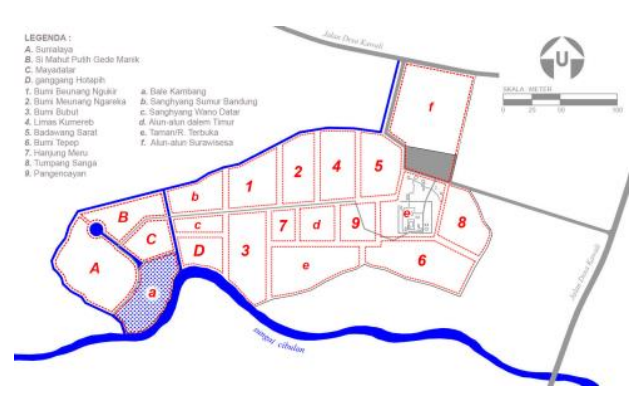

Gambar 5. Tata Ruang Keraton Surawisesa Sumber: Lubis, dkk., 2013.

\section{Tata Ruang Kota Galuh Pakwan}

Budaya perancangan tata ruang kota sudah dikenal sejak zaman prasejarah. Perkembangan tata ruang kota mengalami perkembangan sebagai "wawasan tata ruang" yang melihat bumi sebagai "ruang relatif" dalam perancangan perkotaan, hal ini terjadi seiring perkembangan peradaban manusia (Sujarto, 1992: 3-5). Perencanaan tata ruang sudah menjadi wacana sejak munculnya permukiman-permukiman di lembah Sungai Indus yang disimpulkan oleh para arkeolog sebagai kota paling awal. Mumford (1920) berpendapat bahwa, kota-kota awalnya diciptakan sebagai tawaran solusi terhadap permasalahan tata ruang kawasan di negara-negara Barat, serta menjadi penghubung budaya antarwilayah (Luccarelli, 1990: 1-3).

Pembentukan kota-kota kuno hampir semuanya memiliki kesamaan prinsip yang didasarkan pada kosmologi lokal, dan selalu menempatkan gagasan bahwa "kota adalah negara". Secara umum, kota-kota kuno direncanakan dengan pola dasar linear, sehingga menghasilkan sirkulasi kota yang sejajar dan saling memotong. Bangunan-bangunan ditempatkan pada sisi kanan dan kiri dari sirkulasi, dan menghasilkan pola "papan catur" (Haverfield, 1913: 14-17).

Sebagai ibukota kerajaan, Galuh Pakwan sangat sulit untuk direkonstruksi, selain minimnya tinggalan sejarah sebagai petunjuk, hal serupa hampir bisa ditemui pada bekas kota-kota masa lampau lainnya di Nusantara, yang kesemuanya tidak memiliki pola ruang sebagai kunci analisis tata ruang kota. Michael E. Smith (2007: 1-2) mengatakan bahwa, dalam literatur tentang sejarah tata ruang sebagian besar kota-kota kuno di banyak bagian dunia diklasifikasikan sebagai "tidak terencana", sebagian besar ahli tata kota menyimpulkan jika suatu kawasan kuno tidak memiliki prinsip grid dan sumbu kawasan, maka kawasan tersebut dianggap tidak terencana. Sudut pandang ini mengasumsikan bahwa kota-kota masa lampau di Nusantara berdiri atas "ketidaksengajaan", hal ini sangat etnosentris dan mengabaikan berbagai skema perencanaan perkotaan yang dirancang oleh masyarakat di masa lampau, karena terlalu terpaku pada satu pendekatan modern Barat, dan tidak bisa di berlakukan kepada beberapa kota kuno di Nusantara. Dengan bukti-bukti hasil dari kajian para ahli, setidaknya terdapat tiga kota kuno di Nusantara merupakan hasil sebuah karya rancangan ahli tata kota, yaitu Kota Trowulan, Kota Galuh Pakwan, dan Kota Banda Aceh Darussalam.

Karakteristik dari seni tata kota pada dasarnya berbeda, ia memiliki sifat fisik, sifat tingkatan seni yang terintegrasi, pertimbangan lingkungan alam, dan proses kegiatan manusianya (Qiao, 2017: 4). Dalam menganalisis tata ruang kota kuno dibutuhkan pendekatan dari berbagai sudut pandang serta beberapa bidang keilmuan. Terdapat dua komponen dalam perencanaan kota di kota-kota paling awal, yaitu koordinasi antara bangunan dengan "ruang" di dalam kota, dan standardisasi di antara elemen-elemen bagian kota. Dua komponen tersebut berfungsi untuk menjelaskan makna dan konteks sosial dari tata ruang kota kuno, yang sukar dipahami dari sudut pandang ilmu arkeologi, sekaligus untuk menjawab pertanyaan tentang makna konteks lingkungan binaan dalam kaitannya dengan simbolisme kosmologis dan supernatural yang seringkali diterapkan dalam bangunan dan tata ruang kota kuno (Smith, 2007: 7-30).

Pusat bekas Kota Galuh Pakwan terletak di Situs Astana Gede Kawali, 
Kecamatan Kawali, Kabupaten Ciamis, Provinsi Jawa Barat. Secara astronomi, kawasan ini berada pada koordinat $07^{\circ} 11^{\prime} 24.4$ " LS - 108 $21^{\prime} 45.9^{\prime \prime}$ BT, di ketinggian +404 MdPL, letaknya berada di kaki Gunung Sawal bagian timur. Berdasarkan interpretasi terhadap naskah Carita Ratu Pakuan dan prasasti Kawali I, Kota Galuh Pakwan bisa dipastikan lahir dari proses perencanaan yang matang, sehingga menghasilkan desain kota yang baik dan ideal sebagai pusat kerajaan.

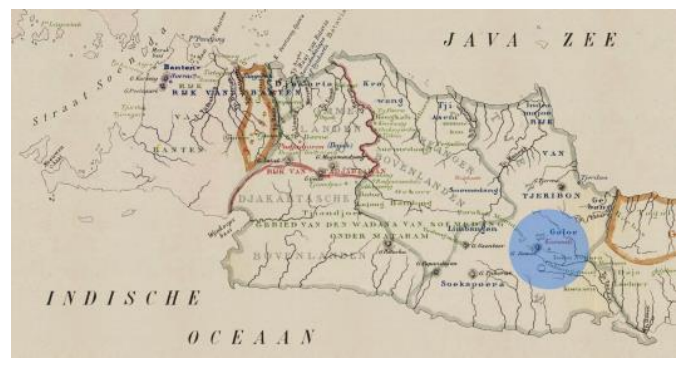

Gambar 6. Keletakan Kota Galuh Pakwan Sumber: Historische kaart van Java. Collectie Koninklijk Instituut vor Taal-, Land-, en Volkenkunde, 1980.

\section{Rekonstruksi Kota Galuh Pakwan}

\section{a. Kosmologi Kota Galuh Pakwan}

Galuh Pakwan merupakan kota yang didesain dengan konsep yang berangkat dari budaya masyarakat Sunda yang sangat dekat dengan alam, bukan sebuah kota yang dibangun berdasarkan konsep mandala Hindu seperti kota-kota tinggalan kerajaan-kerajaan Jawa Tengah dan Jawa Timur. Donald Maclaine Campbell (1915: 54) menegaskan bahwa, jarangnya temuan arca-arca Hindu di wilayah Tatar Sunda menandakan bahwa Brahminisme maupun Buddhisme tidak pernah menjadi sangat populer dalam masyarakat Sunda.

Nina Herlina Lubis, dkk. (2013: 279) menjelaskan bahwa, ajaran Hindu yang dianut oleh masyarakat Sunda tidaklah sepenuhnya dijalankan sesuai dengan ajaran dari tempat asalnya. Rajaraja Sunda tidak terlalu menekankan pada pembangunan candi-candi atau pembuatan arca-arca dewa yang monumental seperti di Jawa Tengah dan Jawa Timur. Kedudukan dewa-dewa Hindu berada di bawah hyang dalam ritual keagamaan masyarakat Sunda. Maka tak mengherankan apabila karya tata kota dengan arsitektur dari Tatar Sunda tidak sedikit pun mencirikan agama Hindu, karena setiap apa yang dibangun oleh masyarakat Sunda, selalu bersandar pada ajaran karuhun yang berangkat dari konsep kabuyutan. Hal tersebut lebih ditegaskan oleh Joyce Marcus dan Jeremy A. Sabloff (2008: 9) bahwa, kota-kota pada masa lampau dibangun oleh masyarakatnya sebagai "entitas", bukan dibangun sebagai sebuah organisme.

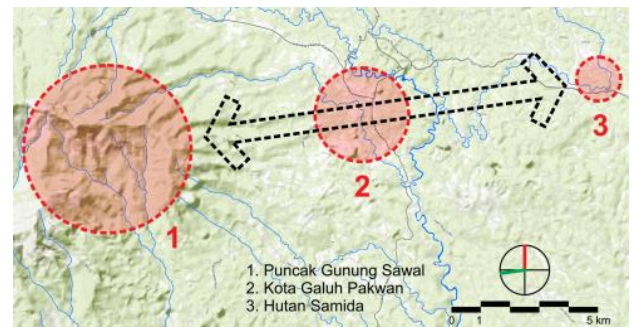

Gambar 7. Kosmologi Kota Galuh Pakwan Sumber: Budimansyah, 2019.

Dalam konsepsi teologis masyarakat Sunda kuna pemilik segala kekuasaan adalah hyang, sebagai pengendali seluruh kekuatan alam yang berpusat di Kahyangan sebagai persemayamannya, sebagai tempat paling tinggi dan ruang tanpa batas yang disimbolkan secara fisik melalui puncak-puncak gunung (meru) (Saringendyanti, 2018: 58-59). Berdasarkan pada uraian di atas, maka sebagai simbol kahyangan tempat para hyang yang dijadikan sebagai pusat kosmologi Kota Galuh Pakwan adalah Gunung Sawal, dengan ketinggian +1.764 mdpl merupakan gunung tertinggi pada wilayah Kerajaan Galuh. Kosmologi tata ruang Kota Galuh Pakwan bisa dilihat pada peta di atas (gb. 7).

Implementasi dari menyelaraskan makrokosmos dengan mikrokosmos pada kehidupan nyata adalah dengan konsep tata ruang kota, hal tersebut dengan jalan 
membentuk sebuah garis linear yang berorientasi pada satu gunung tertentu sebagai sumbu kosmologis. Pada beberapa temuan, kota-kota kuno di Tatar Sunda sangat berbeda dengan kota-kota kuno di Jawa Tengah dan Jawa Timur yang selalu memiliki orientasi utara-selatan (Falah, 2018: 45). Orientasi utara-selatan ataupun timur-barat, tidak menjadi faktor yang mutlak pada kota-kota kuno di Tatar Sunda, karena posisi dari kabuyutankabuyutan yang dipilih menjadi pusat orientasi, sebagai sikap kepasrahan terhadap para hyang. Nina Herlina Lubis, dkk. (2016: 17) menambahkan bahwa, arah penjuru mata angin pada hakikatnya merupakan angan-angan dalam keluasan alam semesta ini. Wilayah tersebut bersifat dunia atas tempat para hyang bersama makhluk-makhluk suci, roh para leluhur, dan roh para pemimpin yang saleh.

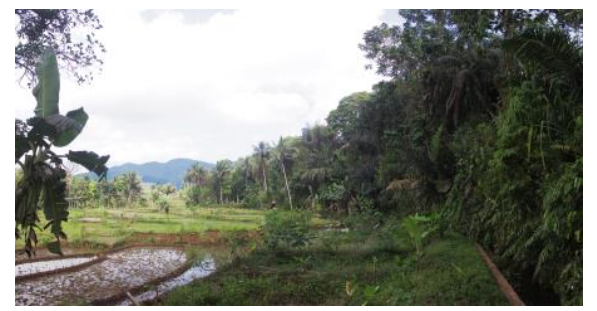

Gambar 8. Area Sisi Selatan Galuh Pakwan Sumber: Budimansyah, 2019.

\section{b. Tinjauan Tata Ruang Kota Galuh Pakwan Melalui Toponimi}

Warisan budaya tertua manusia adalah penamaan tempat di muka bumi. Namanama tempat telah diwariskan kepada setiap generasi secara turun-temurun dalam rentang waktu yang panjang. Toponimi (penamaan tempat) merupakan refleksi dari segala interaksi antara manusia dengan alam melalui dimensi waktu secara terus-menerus, juga sebagai kesadaran meta-linguistik dan historis dari rekaman suara-suara pada masa lampau. Fungsi dari nama tempat adalah sebagai representasi tekstual (lanskap sejarah), karena penciptaan nama tempat berfungsi untuk mendeskripsikan daerah atau tempat yang dimaksud, dan berurusan dengan nilai historis yang sangat penting. Dengan penelusuran melalui nama tempat, kita bisa membaca banyak detail dari sejarah daerah tersebut (Helleland; Ore; dan Wikstrøm, 2012: 1-2).

Keterikatan masyarakat Sunda dengan alam yang terkait dengan toponimi tidak bisa dipisahkan satu sama lain, hal tersebut telah beriringan dalam waktu yang sangat panjang. Dalam konteks ruang dan waktu, toponimi telah menjelma menjadi budaya dan tradisi dari kehidupan sosial masyarakat Sunda. Nilai-nilai apektif, konsep dan hal-hal yang bersifat teoretik, serta kandungan makna yang berimplikasi terhadap tindakan sosial telah berhasil diwariskan melalui toponimi dengan jalan panjang, yang bisa menyesuaikan dengan dinamika sosial budaya masyarakat secara dinamis. Maka, toponimi merupakan media pemaknaan yang luas dari berbagai hal pada masyarakat Sunda (Gunardi, dkk., 2015: 369).

Penelitian mengenai sejarah Kota Galuh Pakwan merupakan sebuah pekerjaan yang sangat sulit, minimnya sumber dan tinggalan arkeologis membuat wacana ini jarang dijadikan lahan penelitian. Berangkat dari hal tersebut, penulis mencoba membuat suatu pilihan untuk melacak lanskap historis Kota Galuh Pakwan melalui toponimi dengan melakukan wawancara kepada para narasumber di Kecamatan Kawali dan sekitarnya. Hasil dari wawancara tersebut adalah sebagai berikut:

1) Astana Gede Kawali

Selain sebagai sebuah kabuyutan, Astana Gede Kawali merupakan pusat penyebaran Islam. Hal tersebut dapat dilihat dari keberadaan makam Pangeran Usman, yang dipercaya sebagai murid Sunan Gunung Jati yang diberi tugas untuk menyebarkan Islam di Kawali. Nama Kawali berasal dari kata $k a$ dan awalan, yang memiliki pengertian sebagai suatu permulaan. Kawali juga berasal dari kata ka dan wali, yang artinya 
mendatangi para wali (auliya) untuk memohon petunjuk (Dipraja, 2017).

2) Sindang/Sindangsari

Tempat istirahat Prabu Darmakusuma pada saat berburu hewan. Sindang dalam bahasa Sunda memiliki pengertian mampir atau berhenti sejenak untuk beristirahat (Gusmara, 2018).

3) Gosali/Ci Empu

Gosali atau Ci Empu pada masa lampau merupakan tempat para panday (Mpu) melakukan aktivitas penempaan logam untuk dijadikan senjata, perkakas pertanian, alat musik (gamelan), dll. (Gusmara, 2018).

4) Ci Tangsi

Tangsi dalam bahasa Sunda artinya adalah penjara atau kerangkeng, tempat hukuman bagi orang-orang yang melakukan kejahatan. Ci Tangsi pada masa lampau adalah penjara dari Kerajaan Galuh. (Gusmara, 2018; Sutardi, 2019).

5) Winduraja

Winduraja berasal dari kata windu yang artinya lingkaran/ikatan) dan raja sebagai pemimpin. Winduraja mengandung pengertian sebuah tempat pertemuan/musyawarah antara Maharaja dengan para Prabu pada masa Kerajaan Galuh (Gusmara, 2018).

6) Kiara Lawang

Kiara (ficus benjamina) adalah sebuah pohon keras endemik Tatar Sunda yang memiliki karakter batang tegak lurus dan tinggi. Sedangkan lawang berarti pintu atau gerbang. Kawasan ini dipercaya sebagai gerbang Kota Galuh Pakwan. Fungsi kawasan pada saat ini adalah pasar dan terminal Kecamatan Kawali (Gusmara, 2018; Sutardi, 2019).

7) Linggapura

Dinamakan Linggapura karena dahulunya di kawasan ini terdapat sebuah batu tegak di puncak bukit (Gusmara, 2018; Permana, 2018).

8) Dayeuh Luhur
Merupakan sebuah kerajaan kecil (vassal) bagian dari Kerajaan Galuh yang didirikan oleh Syeh Ali anak dari eyang Singacala, seorang penyebar agama Islam pertama dari Cirebon (Permana, 2018).

9) Rajadesa

Kerajaan kecil (vassal) bagian dari Kerajaan Galuh yang didirikan oleh Prabu Sirnaraja atau Sirnajaya. Kerajaan ini sebagai penghasil keramik/porselen (Koswara, 2018).

10) Sanghyang

Bukit tempat bersemayamnya para karuhun. Pada area ini terdapat beberapa makam kuno dan struktur batuan budaya prasejarah (Koswara, 2018; Mulyana, 2018).

11) Lumbung

Pada masa Kerajaan Galuh, kawasan ini merupakan area pertanian yang sangat luas. Lumbung berarti sebuah bangunan tempat menyimpan hasil pertanian (padi), yang dalam istilah Sunda disebut leuit. Pada saat sekarang, kawasan ini masih merupakan persawahan yang sangat luas (Enjo, 2018).

12) Wangun

Diceritakan seorang ksatria yang bernama Jagasakti keturunan dari daerah Lumbung ketika membuka daerah baru (ngababakan) untuk membangun permukiman warga $($ ngawangun $=$ membangun $)($ Enjo, 2018).

\section{c. Rekonstruksi Kota Galuh Pakwan}

Sebagaimana telah dijelaskan sebelumnya bahwa sumber terkait sejarah Kota Galuh Pakwan sangat minim, membuat penelitian yang dilakukan sangat rumit. Mark Luccarelli (1990: 10) mengatakan bahwa, alam sekitar telah menjadi cerminan bagi banyak budaya, dan memberikan pengaruh ekologis yang sangat besar, melibatkan semua unsur pembentuk yang terdapat di alam, sehingga menghasilkan lanskap historis sebagai batas wilayah budaya. Hal ini merupakan warisan sosial yang pada 
akhirnya mampu menembus batas-batas fisik. Entitas geografis yang secara alamiah berangkat dari budaya lokal, menjelma menjadi suatu kesadaran ekspresi regionalisme yang salah satunya berwujud toponimi. Toponimi di Kecamatan Kawali dan sekitarnya hasil penelusuran lapangan pada Oktober 2017-November 2019, dan wawancara kepada para narasumber bisa digambarkan sebagai berikut:

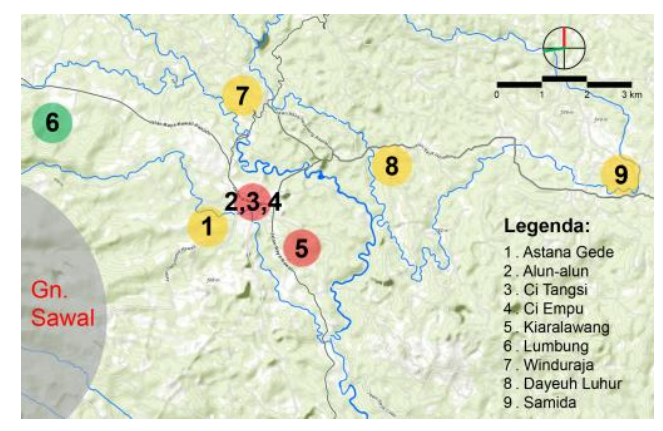

Gambar 9. Peta Toponimi Kawali dsk. Sumber: Budimansyah, 2019.

Berdasarkan peta toponimi di atas yang kemudian diperbandingkan dengan peta kosmologi Kota Galuh Pakwan (gb. 7), bisa dilihat bahwa ploting toponimi di Kecamatan Kawali dan sekitarnya sebagian besar terkonsentrasi pada kawasan Astana Gede Kawali, serta membentuk poros sejajar yang berorientasi ke puncak Gunung Sawal, hal ini semakin memberikan petunjuk terhadap konsep dan pola tata ruang Kota Galuh Pakwan.

Botolv Helleland; Christian-Emil Ore; dan Solveig Wikstrøm (2012: 96) menulis bahwa, penamaan suatu tempat merupakan sinyal sosial milik masyarakat, semakin banyak pemberian nama tempat akan semakin menambah ikatan emosional dalam masyarakat. Sebagai ekspresi sinkronik dan diakronik, dalam kapasitasnya yang melekat pada penamaan yang lebih kecil atau lebih besar, hal tersebut merupakan bagian vital dari bahasa sehari-hari dan menjadi memori kolektif dari seluruh individu masyarakat, yang sejatinya merupakan jenius lokus.
Komponen ruang terdiri dari lahan dan atmosfer. Tanah dan tata air merupakan pembagian dari lahan. Ruang adalah suatu bagian dari alam yang dapat memberi dampak kekacauan jika tidak dikelola dan dipelihara dengan baik dan benar (Rustiadi, dkk., 2011: 391-392). Keberlanjutan bumi beserta kehidupan seluruh penghuninya semakin terancam oleh krisis lingkungan yang semakin memburuk, yang berdampak terhadap bencana banjir, sedimentasi, tanah longsor, dan kelangkaan air. Kesemuanya itu selain bagian dari proses alam, juga peran besar manusia yang tidak bertanggungjawab terhadap pemanfaatan alam secara berlebihan dan tidak terarah (Suyatman, 2018: 77-78). Kehidupan masyarakat Sunda pada masa lampau sangat memegang pikukuh karuhun yang memperlakukan alam dengan penuh hormat. Penghormatan masyarakat Sunda terhadap alam bukan saja diejawantahkan dalam ranah budaya bertani, namun sampai pada wilayah penataan ruang kota sebagai mikrokosmos. Penerapan sikap hidup ekologis tersebut bisa digambarkan sebagai berikut:

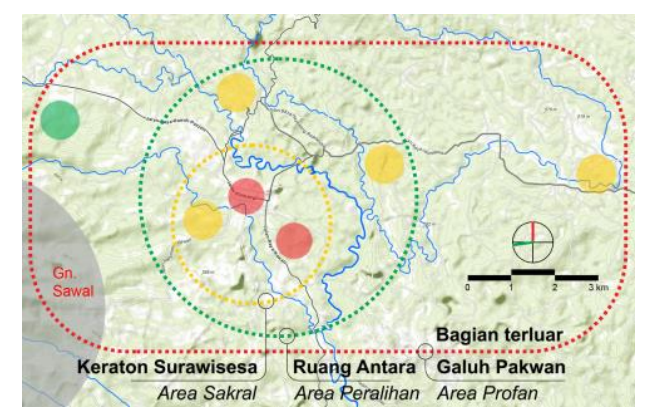

Gambar 10. Konsep Pembagian Zona di Galuh Pakwan. Sumber: Budimansyah, 2019.

Pembagian zona fungsi ruang pada Kota Galuh Pakwan jika ditinjau dari konsep tata kota modern merupakan pola radial-konsentris menerus, dimana fungsifungsi utama (sakral, penting, privat, vital) berada pada kawasan inti (tengah/sentral), kemudian diikuti kawasan di luar zona inti sebagai area transisi (ruang transisi) yang 
bersifat semi publik, dan terakhir kawasan terluar (profan) sebagai zona publik. Oposisi antara ruang inti dan ruang luar (eksternal dengan internal) merupakan sistem adat yang masih dipakai oleh masyarakat Sunda Kanekes, yang dibagi menjadi Baduy Dalam (internal) yang merupakan organisasi yang sakral, serta Baduy Luar (eksternal) sebagai organisasi yang profan (Kartawinata, 2001: 8; Moeis, 2010: 7; Suparmini, Setyawati, dan Sumunar, 2012: 48; Jamaludin, 2013: 48).

Pada sirkulasi Kota Galuh Pakwan bias dilihat sebagai pola radial-konsentris menerus. Pemilihan pola tersebut (seperti juga halnya beberapa kota lampau di Tatar Sunda) didasarkan pada fisik topografi wilayahnya yang memiliki kemiringan bervariasi, serta posisi bukit-bukitnya berada di antara lembah-lembah. Pola ini juga sebagai pembentuk mikrokosmos yang bisa dengan sangat fleksibel menentukan arah orientasi menuju pusat kosmologi sebagai makrokosmos.

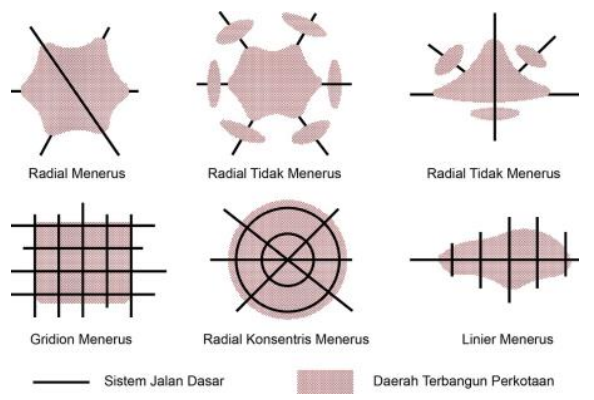

Gambar 11. Pola Umum Perkembangan Kota Sumber: Branch, 1996.

\section{PENUTUP}

Berdasarkan uraian pada bagian analisis dapat disimpulkan bahwa Kota Galuh Pakwan sebagai ibu kota Kerajaan Galuh berawal dari sebuah kabuyutan Sunda. Pada masa pemerintahan Prabu Niskalawastu Kancana, kabuyutan tersebut berubah menjadi pusat politik dengan tetap menjalankan fungsi kabuyutannya. Sebagai sebuah pusat pemerintahan, Galuh Pakwan kemudian menjelma menjadi sebuah kota yang tata ruangnya menunjukkan representasi dan implementasi konsep kosmologi Sunda.

Apabila ditinjau dari nilai-nilai kelokalannya, tata ruang Kota Galuh Pakwan dapat dipahami dengan memperhatikan ploting toponimi di sekitar Kecamatan Kawali sekarang. Hasil rekonstruksi menunjukkan bahwa toponimi di wilayah Kecamatan Kawali tersebut ternyata membentuk poros sejajar yang berorientasi ke Puncak Gunung Sawal.

Bentuk kota tersebut, apabila ditinjau dari konsep tata ruang kota modern, merupakan implementasi dari pola radialkonsentris menerus. Wilayah inti kota merupakan wilayah paling sakral yang bernama Dalem Sri Kancana Manik. Dari wilayah sakral ini, diciptakan wilayah transisi (ruang antara) yang bersifat semi publik yang disebut sebagai Dalem Kalangsu. Ruang paling luar merupakan kawasan profan sebagai zona publik yaitu Dalem Si Pawindu Hurip. Pola kota tersebut merupakan implementasi penghormatan masyarakat Sunda terhadap alam dengan tidak mengubah kondisi alamiahnya secara drastis untuk kepentingan penataan ruang kota, melainkan menyesuaikan penataan kota dengan kondisi alamnya. Oleh karena itu, gambaran kosmologi Sunda yang memperlihatkan hubungan antara makrokosmos dan mikrokosmos bersifat fleksibel sebagaimana terungkap dalam naskah-naksah Sunda kuna.

\section{UCAPAN TERIMA KASIH}

Tulisan sederhana ini tidak akan mungkin bisa terwujud tanpa ridho Allah SWT. Selain itu, tanpa bantuan dari berbagai pihak yang tidak bisa disebutkan satu per satu, penulis menyadari tidak mungkin tulisan ini dapat diselesaikan.

Hasil penelitian ini penulis haturkan kepada para pewaris sejarah dan budaya Sunda, serta kepada para penulis/peneliti yang telah lebih dahulu menelusuri Sunda di masa lampau. Terakhir penulis haturkan terima kasih kepada tim redaksi dan para reviewer Jurnal Patanjala yang telah mengkritisi tulisan ini sehingga menjadi lebih baik lagi. 


\section{DAFTAR SUMBER}

Albulescu, I. (2018). The Historical Method in Educational Research. American Journal of Humanities and Social Sciences Research, 02 (08), 185-190.

Belchera, B. M., Claus, R., Davel, Ramirez, \& L. F. (2019). Linking Transdisciplinary Research Characteristics and Quality to Effectiveness: A Comparative Analysis of Five Research-for-Development Projects. Environmental Science and Policy, 101, 192-203.

Branch, C. M. (1996). Perencanaan Kota Komprehensif: Pengantar dan Penjelasan. Terj. Bambang H. W. Yogyakarta: Gadjah Mada University Press.

Budimansyah, Sofianto, K., \& Dienaputra, R. D. (2018). Sang Hyang Talaga Rena Mahawijaya: Telaga Buatan sebagai Solusi Bencana. Patanjala, 10 (3), 419434.

Budimansyah. (2019). Rekonstruksi Kota Galuh Pakwan (1371 - 1475 M) dan Kota Pakwan Pajajaran (1482 - 1521 M). Tesis FIB UNPAD.

Buckley, P. J. (2016). Historical Research Approaches to the Analysis of Internationalisation. Management International Review, 56 (6), 879-900.

Campbell, D. M. (1915). Java: Past and Present (Vol. I), A Description of the Most Beautuful Country in the World, its Ancient History, People, Antiquities, and Product. London: William Heinemann.

Damayanti, R., \& Handinoto. (2005). Kawasan 'Pusat Kota' dalam Perkembangan Sejarah Perkotaan di Jawa. Dimensi, 33 (1), 34-42.

Danasasmita, Saléh. (2012). Nyukcruk Sajarah Pakuan Pajajaran jeung Prabu Siliwangi. Bandung: Kiblat Buku Utama.

Darsa, U. A. (2007). Carita Ratu Pakuan (Kropak 410). Sundalana 6. Bandung: Pusat Studi Sunda.

Darsa, U. A. (2011). Nyukcruk Galur Mapay Laratan, Pucuk Ligar di Dayeuh Galuh Pakuan. Sundalana 10. Bandung: Pusat Studi Sunda.
Darsa, U. A. (2015). Konsepsi dan Eksistensi Gunung Berdasarkan Tradisi Naskah Sunda, diakses 7 Januari 2019, dari https://www.slideshare.net/erickridzky/ko nsepsi-dan-eksistensigunungberdasarkan-tradisi-naskahsunda-sebuah-perspektif-filologi.

Dhona, H. R. (2016). Wilayah Sunda dalam Surat Kabar Sunda Era Kolonial. Jurnal Komunikasi, 11 (1), 1-16.

Dipraja, J. (8 Oktober 2017). Wawancara.

Enjo. (29 Oktober 2018). Wawancara.

Falah, M. (2018). Pertumbuhan Morfologi Kota-kota Pusat Pemerintahan di Priangan pada Abad XX - Awal Abad $X X I$. Disertasi (Ringkasan). FIB UNPAD.

Gottschalk, L. (2006). Mengerti Sejarah. Terj. Nugroho Notosusanto. Jakarta: UI Press.

Gunardi, G., Mahdi, S., Ratnasari, D., \& Sobarna, C. (2015). Toponimi dan Lingkungan Hidup Kampung Adat di Tatar Sunda. Prosiding Seminar Nasional Riset Inovatif (SENARI) Ke-3 Memperkuat Jati Diri Bangsa melalui Riset Inovatif, Unggul, dan Berkarakter, 369-374. Singaraja: UNDIKSHA.

Gusmara, A. (15 September 2018). Wawancara.

Haverfield, F. (1913). Ancient Town Planning. London: Oxford University Press.

Helleland, B., Ore, C. E., \& Wikstrøm, S. (2012). Names and Identities. Oslo Studies in Language, 4 (2), 1-6.

Herlina, N. (2017, Oktober). Dua Peristiwa dalam Ingatan Kolektif. Pikiran Rakyat, hlm. 1, 11 .

Historische kaart van Java. 1980. Collectie Koninklijk Instituut vor Taal-, Land-, en Volkenkunde. Inv. Nr. DF 5,10. Amsterdam: Tresling.

Hoffmann, S., Pohl, C., \& Hering, J. G. (2017). Methods and Procedures of Transdisciplinary Knowledge Integration: Empirical Insights from Four Thematic Synthesis Processes. Ecology and Society, 22 (1), 1-12.

Isnendes, R. (2005). Semiotika Siliwangi pada Masyarakat Sunda. Jurnal Pendidikan Bahasa dan Sastra, 31, 1-19. 
Jamaludin. (2013). Makna Simbolik Huma (Ladang) di Masyarakat Baduy. Mozaik, 13 (1), 46-54.

Kartakusuma, R. K. (2012). Landasan Spiritual Leluhur 'Tradisi Megalitik' (Kabuyutan) Simbol Kesatuan Etnis Nusantara yang Tercermin dalam Ajaran Sunda. Makalah dalam Sosialisasi Hasil Penelitian Arkeologi Jawa Bagian Barat. Pelabuhanratu: Puslit Arkenas.

Kartawinata, Ade M. (2001). Pamarentahan Baduy di desa Kanekes: Perspektif Kekerabatan. Makalah dalam Simposium Internasional Jurnal Antropologi Indonesia II, 1-15. Padang: UNAND.

Kartodirdjo, S. (1992). Pendekatan Ilmu Sosial dalam Metodologi Sejarah. Jakarta: Gramedia Pustaka Utama.

Koswara, W. (27 Oktober 2018). Wawancara.

Lorenz, C. (2001). History: Theories and Methods. Dalam Neil J. Smelser dan Paul B. Baltes (Ed.), International Encyclopedia of the Social \& Behavioral Sciences (hlm. 6869-6876). Amsterdam: Elsevier.

Lubis, N. H., Marlina, I., Hardjasaputra, A. S., Dienaputra, R. D., Muhsin Z., M., \& Sofianto, K. (2000). Sejarah Kota-kota Lama di Jawa Barat. Jatinangor: Alqaprint.

Lubis, N. H., Saringendyanti, E., Darsa, U. A., Falah, M., \& Budimansyah (2013). Sejarah Kerajaan Sunda. Bandung: YMSI Jawa Barat dan MGMP IPS SMP Kab. Purwakarta.

Lubis, N. H., Muhsin Z., M., Sofianto, K., Mahzuni, D., Widyonugrohanto, Mulyadi, R. M., \& Darsa, U. A. (2016). Rekonstruksi Kerajaan Galuh Abad VIIIXV. Paramita, 26 (1), 9-22.

Luccarelli, M. (1990). Planning and Regionalism in the Early Thought of Lewis Mumford. The Hudson Valley Regional Review, 7 (1), 1-19.

Marcus, J. and Sabloff, J. A. (Ed.). (2008). The Ancient City: New Perspectives on Urbanism in the Old and New World. Santa Fe: School for Advanced Research Press.
Mayer, H., Sager, F., Kaufmann, D., \& Warland, M. (2016). Capital City Dynamics: Linking Regional Innovation Systems, Locational Policies and Policy Regimes. Cities, 51, 11-20.

Moeis, Syarif. (2010). Konsep Ruang dalam Kehidupan Orang Kanekes. Makalah dalam Diskusi Jurusan Pendidikan Sejarah FPIPS, 1-16. Bandung: UPI.

Muhsin Z., M. (2011). Eksistensi Kerajaan Pajajaran dan Prabu Siliwangi. Makalah dalam Seminar Prodi Ilmu Sejarah, 1-17. Jatinangor: FASA UNPAD.

Muhsin Z., M., Mahzuni, D., \& Septiani, A. (2019). Pengobatan Alternatif Penyakit Tulang: Studi Kasus Kearifan Lokal Para Terapis Penyakit Tulang di Wilayah Jawa Barat. Patanjala, 11 (3), 431-448.

Mulyana, Y. (27 Oktober 2018). Wawancara.

Munandar, A. A. (2017, Oktober). Perang Bubat dalam Naskah Kuno. Pikiran Rakyat, hlm. 1, 11.

Paddison, R. (Ed.). (2001). Handbook of Urban Studies. London: Sage Publications.

Permana, I. (28 Oktober 2018). Wawancara.

Permana, R. C. E. (2006). Tata Ruang Masyarakat Baduy. Jakarta: Wedatama Widya Sastra.

Prijono, S. (2015). Pola Persebaran Tinggalan Budaya Megalitik di Leuwisari, Tasikmalaya. Forum Arkeologi, 28 (2), 69-78.

Purwani, O. (2017). Javanese Cosmological Layout as a Political Space. Cities, 61, 7482.

Rigg, J. (1862). A Dictionary of The Sunda Language of Java. Batavia: Lange \& Co.

Rustiadi, E., Saefulhakim, S., Panuju, D. R. (2011). Perencanaan dan Pengembangan Wilayah. Jakarta: Yayasan Obor Indonesia.

Qiao, Y. (2017). City, Urban Planning and the Creation of Urban Culture - Taking the Ancient City of Xi'an as an Example. MATEC Web of Conferences, 100, 1-6. 
Sabaruddin, A. (2012). Arsitektur Perumahan di Perkotaan. Bandung: Puslitbangkim, Kementerian PUPR.

Saringendyanti, E. (2018). Sunda Wiwitan di Tatar Sunda pada Abad V - Awal XXI: Perspektif Historis-Arkeologis. Disertasi (Ringkasan) FIB UNPAD.

Saringendyanti, E., Yondri, L., Falah, M., Irama, W., Budimansyah, Junaedi, A. A., Septiani, A., Jejen, D., \& Saripudin, D. (2019). Laporan Penelitian: Tata Ruang Keraton Galuh (IX-X M) dan Keraton Surawisesa (XIV-XVM). Bandung: Balar Jabar.

Savitri, M. (2015). Peran Magis-Religius Bengawan Solo. Kalpataru, 24 (1), 37-46.

Scott, A. J. dan Storper, M. (2015). The Natura of Cities: The Scope and Limits of Urban Theory. International Journal of Urban and Regional Research, 39 (1), 1-15.

Smith, M. E. (2007). Form and Meaning in the Earliest Cities: A New Approach to Ancient Urban Planning. Journal of Planning History, 6 (1), 3-47.

Singh, R. P. B. (1993). Cosmic Layout of the Hindu Sacred City, Varanasi (Benares). Arch. \& Behav, 9 (2), 239-250.

Sujarto, D. (1992). Wawasan Tata Ruang. Jurnal Perencanaan Wilayah dan Kota, 3 (4a), 3-8.

Suparmini, S. S., \& Sumunar, D. R. S. (2012). Laporan Penelitian: Pelestarian Lingkungan Masyarakat Baduy Berbasis Kearifan Lokal. Yogyakarta: FIS UNY.

Susilawati. (2006). Konservasi Tanah dan Air di Daerah Semi Kering Provinsi Nusa Tenggara Timur. Jurnal Teknik Sipil, 3 (1), 33-43.

Sutardi, D. (9 November 2019). Wawancara.

Suyatman, U. (2018). Teologi Lingkungan dalam Kearifan Lokal Masyarakat Sunda. Al-Tsaqafa, 15 (01), Juli 2018, 77-88.

Tolla, M. (2014). Landscape and Orientation of Megalithic Chambers in MecklenburgVorpommern (North Germany): Phenomenology Perspective. Рариа, 6 (2), 135-141.
Umemoto, K. dan Zambonelli, V. (2012). Cultural Diversity. Dalam Randall Crane dan Rachel Weber (Ed.), The Oxford Handbook of Urban Planning (hlm. 197222). UK: Oxford University Press.

Wibisono, S. C. (2013). Irigasi Tirtayasa: Teknik Pengelolaan Air Kesultanan Banten pada Abad ke-17 M. Amerta, 31 (1), 53-68.

Widyonugrahanto, Lubis, N. H., Muhsin Z., M., Mahzuni, D., Sofianto, K., Mulyadi, R. M., \& Darsa, U. A. (2017). The Politics of Sundanese Kingdom Administration in Kawali-Galuh. Paramita, 27 (1), 28-33.

Young, T. Z. (2016). Maya Political Organization During the Terminal Classic Period in the Cochuah Region, Quintana Roo, Mexico, from the Perspective of a Secondary Site. Disertasi. College of Liberal Arts, Temple University. 
